\title{
Solar Atlas for the Southern and Eastern Mediterranean
}

\author{
Carsten Hoyer-Klick ${ }^{1}$, Lucien Wald ${ }^{2}$, Lionel Menard ${ }^{2}$, Philippe Blanc ${ }^{2}$, Etienne Wey ${ }^{3}$, Marcel Suri ${ }^{4}$, \\ Tomas Cebecauer ${ }^{4}$, Thomas Huld ${ }^{5}$, Houda Allal ${ }^{6}$, Amel Bida $^{7}$, Maged Mahmoud ${ }^{7}$, Ludger Lorych ${ }^{7}$, \\ Daniel Puig ${ }^{8}$, Marcel Caner ${ }^{8}$, Marion Schroedter-Homscheidt ${ }^{9}$, Christoph Schillings $^{1}$, \\ Thomas Wanderer ${ }^{1}$ \\ ${ }^{1}$ German Aerospace Center, Institute of Technical Thermodynamics, Department of Systems Analysis and Technology \\ Assessment, Pfaffenwaldring 38-40, 70569 Stuttgart, Germany, Tel. +49 7116862 728, carsten.hoyer-klick@dlr.de. \\ ${ }^{2}$ MINES ParisTech, Sophia Antipolis, France \\ ${ }^{3}$ Transvalor, Sophia Antipolis, France \\ ${ }^{4}$ GeoModel Solar, Bratislava, Slovak Republic, \\ ${ }^{5}$ Joint Research Center, Ispra, Italy, \\ ${ }^{6}$ Observatoire Méditerranéen de l'énergie, Paris, France \\ ${ }^{7}$ RCREEE (Regional Center for Renewable Energy and Energy Efficiency), Cairo, Egypt \\ ${ }^{8}$ United Nations Environmental Programme, Paris, France \\ ${ }^{9}$ German Aerospace Center, German Remote Sensing Data Center, Oberpfaffenhofen, Germany
}

\begin{abstract}
Southern and eastern Mediterranean regions are prone to production of electricity by solar systems. The solar resource is the "fuel" of such systems and its availability is a key economic parameter in system design. Even though the southern and eastern Mediterranean region is served by several commercial data providers, in a public domain, so far only coarse resolution $(100 \mathrm{~km})$ data or data with limited temporal coverage is available. For more rapid development of policies and to attract the industrial interest in this region a more enhanced and easy to access free information is needed.

The project will bring high resolution $(1 \mathrm{~km})$, long term coverage of at least 15 years data on the available solar resources for the region covering the countries Syria, Jordan, Israel, Lebanon, Egypt, Libya, Tunisia, Algeria, Morocco, Palestine National Authority, Mauretania and Turkey. The resource data will be derived from Earth Observation satellite data, based on published and transparent methodologies and the data will be validated with existing ground measurements in the region. The database will be provided by SOLEMI and Helioclim-3 (SoDa) sources - Global Horizontal Irradiation (GHI) and Direct Normal Irradiation (DNI). The data will be made available via a distributed information system which will ensure the ease of access to the data. The free access to the data will include historical, annual and monthly averages, and more detailed data products and services will remain the domain of commercial data providers.

This paper will show the first prototype of the user interface for an easy web access to the solar radiation as well as ancillary geographical data. With the presentation of this paper we aim to encourage potential users to give us feedback on the further development.
\end{abstract}

Keywords: solar radiation, direct normal radiation, atlas, solar energy potentials.

\section{Introduction}

Solar energy has a large potential for renewable energy generation. Solar energy is highly variable in space and time. High resolution mapping is therefore essential for successful policy and project development. Precise knowledge of the available solar resource in high spatial resolution and over a long period of time is needed for the evaluation of spatial and temporal variability, especially for site qualification and design of power plants. 


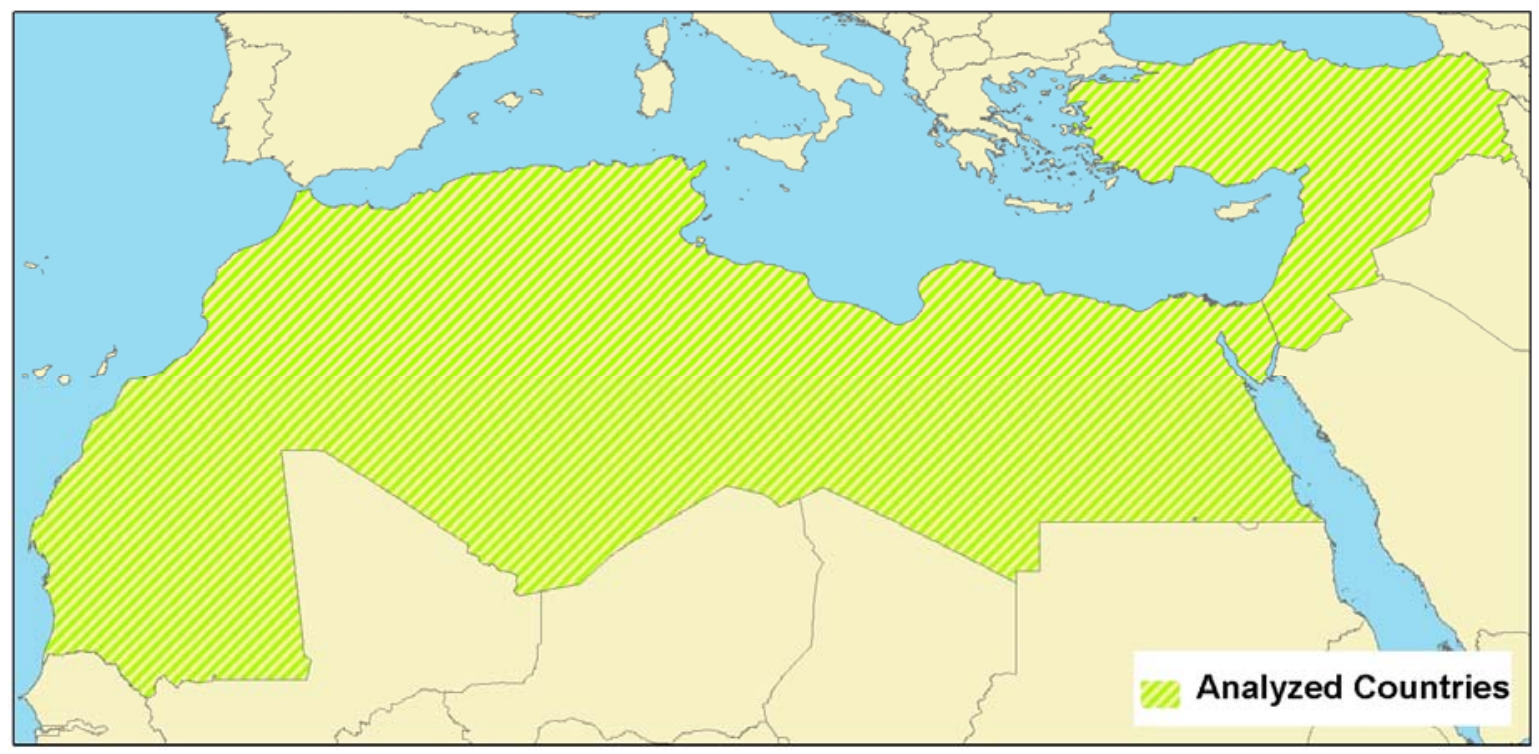

Figure 1: Analyzed Countries for Solar Atlas for the Mediterranean.

Besides commercial databases as SolarGIS[15], Helioclim-3[16] and 3 TIER, no free database exits which is based on long term data and high resolution. Global long term databases (as e.g. NASA SSE) have only coarse resolution (NASA SSE $100 \mathrm{~km}$, Helioclim-1, $30 \mathrm{~km}$, but no direct normal irradiation) or high resolution data has been processed only for limited regions or only short periods of time (e.g. the DLR MEDCSP containing only data of 2002). The set up of a 1x1 km long term map will be a significant step forward in solar resource assessments in the Mediterranean compared to the present situation lowering the risks in solar energy investments. Table 1 shows the available data sets which cover more than one country in the region. There are some additional maps on a country by country base, but these mostly are done by interpolation of ground measurements and only cover global horizontal data with an annual average mean.

\begin{tabular}{|l|l|l|l|l|l|}
\hline Data set & NASA SSE & Reanalysis & NREL CSR & Helioclim1 & $\begin{array}{l}\text { MED-CSP / } \\
\text { SOLEMI }\end{array}$ \\
\hline Parameters & $\begin{array}{l}\text { Global } \\
\text { radiation, } \\
\text { Wind Speed }\end{array}$ & $\begin{array}{l}\text { Direct normal } \\
\text { irradiance, Wind } \\
\text { Speed }\end{array}$ & $\begin{array}{l}\text { Direct normal } \\
\text { irradiance }\end{array}$ & Global & $\begin{array}{l}\text { Direct normal } \\
\text { irradiance }\end{array}$ \\
\hline $\begin{array}{l}\text { Spatial } \\
\text { resolution }\end{array}$ & $1^{\circ} \times 1^{\circ}$ & $1.125^{\circ} \times 1.125^{\circ}$ & $40 \mathrm{~km}$ & $30 \mathrm{~km}$ & $\begin{array}{l}0.5 \text { arcmin } ~ \\
\text { km }\end{array}$ \\
\hline Spatial coverage & Global & Global & Global & $\begin{array}{l}\text { Europe, Africa, } \\
\text { Western Asia }\end{array}$ & $\begin{array}{l}\text { Europe, Africa, } \\
\text { Most of Asia }\end{array}$ \\
\hline $\begin{array}{l}\text { Temporal } \\
\text { coverage }\end{array}$ & $\begin{array}{l}\text { July } 1983- \\
\text { June } 1993\end{array}$ & $1979-1993$ & & $1985-2005$ & $\begin{array}{l}2002 \\
(1991-2005 \\
\text { possible })\end{array}$ \\
\hline
\end{tabular}

Table 1: Comparison of the properties of the different non-commercial resource data sets.

High quality ground measurements of direct normal radiation are very scarce. The only data sets which cover at least hourly global horizontal and direct normal radiation available to the public in the south Mediterranean are the BSRN (Baseline Surface Radiation Network of the World Meteorological Organization - WMO) stations in Tamanrasset (Algeria) and SedeBoqer (Israel). Therefore only satellite based assessments can be used to derive the available solar resource in the Mediterranean on a long term basis. Most measurements in the region are currently done by commercial project developers which usually do not give access to their measured data.

Stakeholders from the South and East Mediterranean have clearly expressed the need for high quality resource assessments within the recently finished EC project REMAP[1][2][3]. The project REMAP collected available resource data which proved to be insufficient in spatial resolution and temporal coverage. The need for resource data was additionally expressed in a recent stakeholder workshop with organizations 
working in Morocco, Algeria and Egypt within the project enerMENA [4].

Besides the data itself, easy access to the data over the internet is very important. The best data set is worth nearly anything if it cannot be used by the people who want to support or invest into solar energy. PVGIS [5] is a good example of such a service. The solar radiation data can be accessed via a Web portal and small applications help in the first analysis steps in exploiting the available data. Within the Solar Atlas for the Mediterranean we want to build up a platform which delivers easy access to monthly solar radiation data covering the time period 1991-2010 and a number of tools with help the users to efficiently exploit the data which is available on the portal. The data can be downloaded as monthly values for specific sites, but also maps can be extracted for further analysis e.g. within geographic information systems (GIS).

The Mediterranean Solar Atlas is targeting a broad range of users, from installers or planner of small systems (rooftop PV and solar water heating) over project development companies for larger projects which need a first estimation to start the development of the projects, to governmental and public organizations which need information on solar energy potentials to develop successful policies to support the introduction of solar energy into the local/national energy system.

The project of the Mediterranean Solar Atlas aims to serve free basic solar resource information with enhanced detail in order to increase the awareness and to lower the risk in the preliminary decisions of policy makers and investors. Thus it aims to be a part of a successful business environment contributing to more rapid development of solar energy in the target region. The Atlas offers only basic information while letting other companies and service providers to focus on customized and value-added services based on specialized commercial data products and consultancy services.

The project runs until September 2012 and currently the user interface is being developed. To improve the usability of the interface the feedback by its future users is very important. It is the intention of the project's partners to provide a useful portal to the users in the southern Mediterranean. The feedback by the users will help to improve the portal and make it more useful to the users. The current prototype can be accessed at http://www.solar-med-atlas.com and a feedback questionnaire is available on the website.

\section{Data}

The first information available is the amount of global horizontal and direct normal radiation on a 30 arc second grid. The available solar radiation is mapped from geostationary satellite images. State of the art methods will be used to derive hourly solar radiation for each grid point of area. The methodology is described in detail for direct normal irradiance in [6] and for global irradiance in [7] and [8]. The data covering the time period 1991-2005 will be from the SOLEMI [9] archive of DLR, the data 2006 to 2010 from the Helioclim archive of Mines ParisTech [10]. The methods will be enhanced by the use of a new aerosol data set based on the MATCH model [11], which will provide daily aerosol information on a $1.9^{\circ}$ grid to achieve an improved DNI modeling, as aerosols are one of the most important factors influencing DNI in the southern and eastern Mediterranean.

The second addition to the methods is the use of a horizon data base. In complex terrain with higher mountains in the near surroundings their shading can significantly reduce the availability of solar radiation. A horizon data base has been created on the base of a high resolution digital elevation model from the Shuttle Radar Topography Mission which has a spatial resolution of $90 \mathrm{~m}$ and $6 \mathrm{~m}$ in height. A $360^{\circ}$ horizon line is determined for each grid point of the data set.

Solar radiation is not the only information necessary for the assessment of solar energy potentials and projects. The atlas will deliver also additional geographical information as land use, land cover, water bodies, protected areas and infrastructure data. Suitable land areas and access to infrastructure (e.g. power lines, streets), access to cooling water can be important factors for successful project development. Web-GIS applications will help to narrow down promising sites for project development.

Investors into smaller systems can directly use the provided monthly data into their simulation tools to optimize their system layout and design. Simple tools will help them to estimate the yield of a PV system or 
to calculate the incoming radiation to an arbitrary oriented plane.

This information can also be used to narrow down potentials by using only suitable land areas e.g. with a certain maximum distance to infrastructure as streets or power lines. This helps in the assessment of potential markets (for manufactures, investors, politics) and the development of well suited policies to introduce solar energy into the overall energy system. These assessments profit from information about socio-economic framework conditions. Data on the energy system, support conditions can be queried from various data bases such as REN21[12], REEGLE[13] and the World Bank[14].

The data will be provided on an open architecture which is based on the recommendations on the GEOSSADC (Global Earth Observation System of Systems -Architecture and Data Committee) and OGC (Open Geospatial Consortium). The data will be available as Web services which use these standards. The tools will be implemented in order to allow access to data via Web Processing Services (WPS). Due to the open and distributed architecture these services could also be incorporated into other portals and software tools.

\section{User Interface}

Creating high quality resource data is the first task in creating a database for the successful deployment of solar energy. Making it available to the users is the second task.

The user interface which is currently being designed uses the Google maps API and builds on the experience from the SolarGIS commercial system [15]. This brings all the features users know from Google Maps and the data available within Google Maps into the Solar Mediterranean Atlas

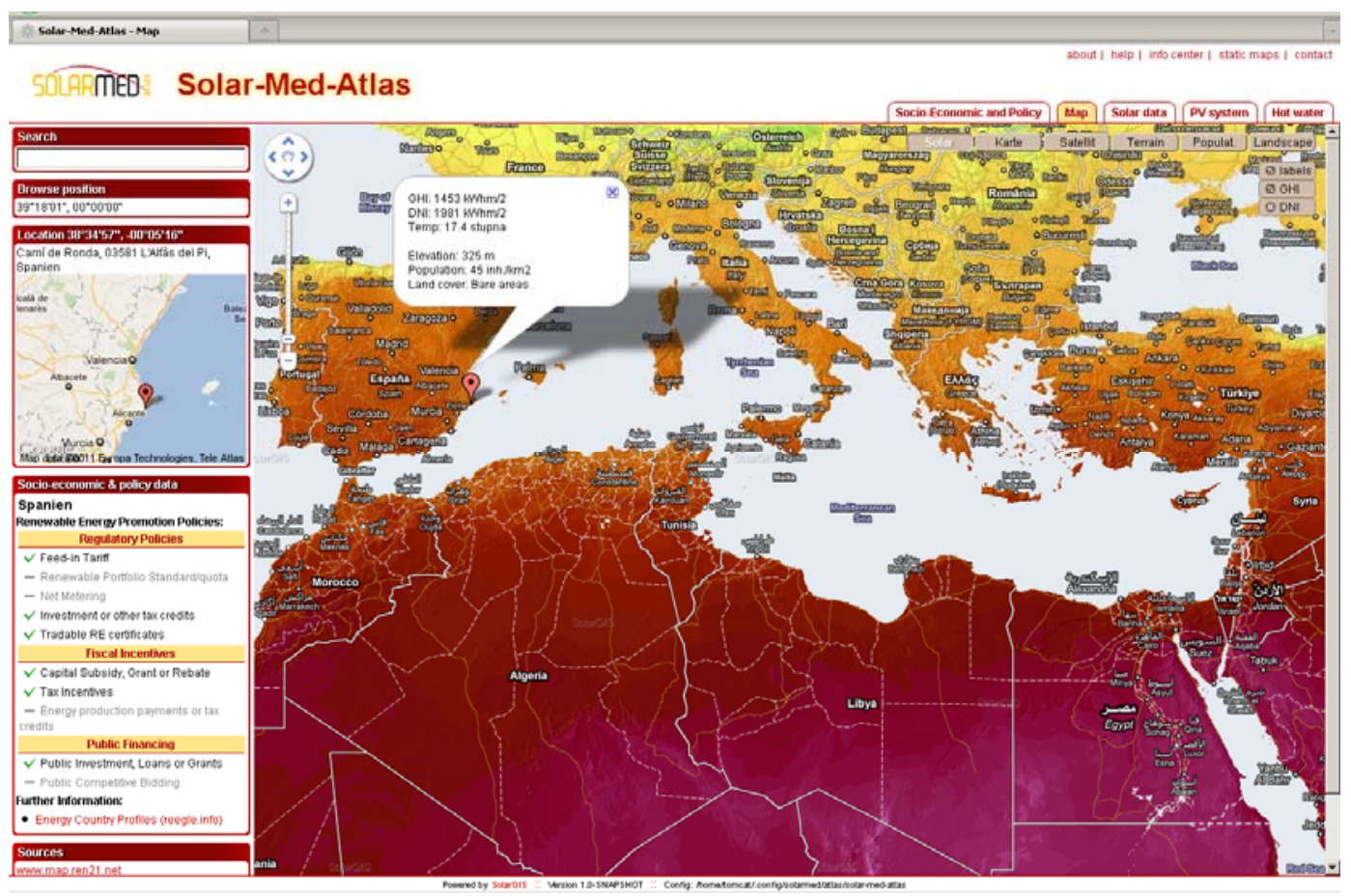

Figure 2: Main map windows of the Atlas

The main window consists of the solar radiation map, which can be scrolled and zoomed. The search field can be used to find a site. Everything known from Google Maps can be entered, city names, coordinates, complete addresses. The small map on the left shows the surrounding area of the selected site. The box below shows some aggregated information on socio-economics and policies, e.g. the available supporting policies.

The main window has several taps. The Socio-Economic and Policy window does an analysis of the connected data bases and brings more detailed data and links to documents describing the socio-economic 
and policy information.

The map tap gives access to the solar radiation and other maps. It shows the direct normal and global horizontal radiation, by clicking into the site marker the site specific annual average global and direct normal radiation can be read. Other maps show terrain (elevation), population density and landscape. The map and satellite taps correspond to the standard Google Maps view.

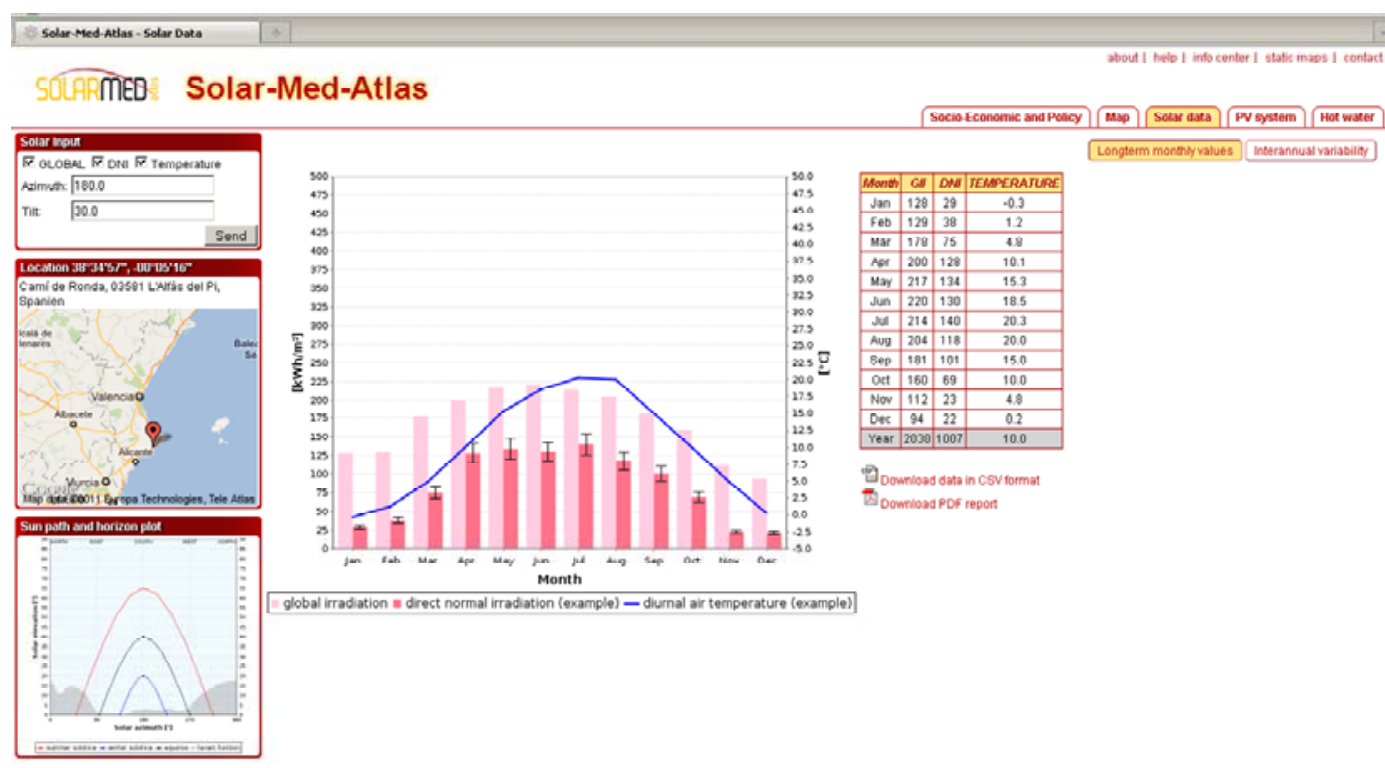

Figure 3: Example of the presentation of the solar radiation data.

The solar data tap shows the average monthly distribution of the solar radiation at the selected site. On the left-hand side there is a plot of the sun path and the local horizon. The data can be downloaded here in pdf and CSV format. The tab can also show the inter-annual variability of the solar radiation. 


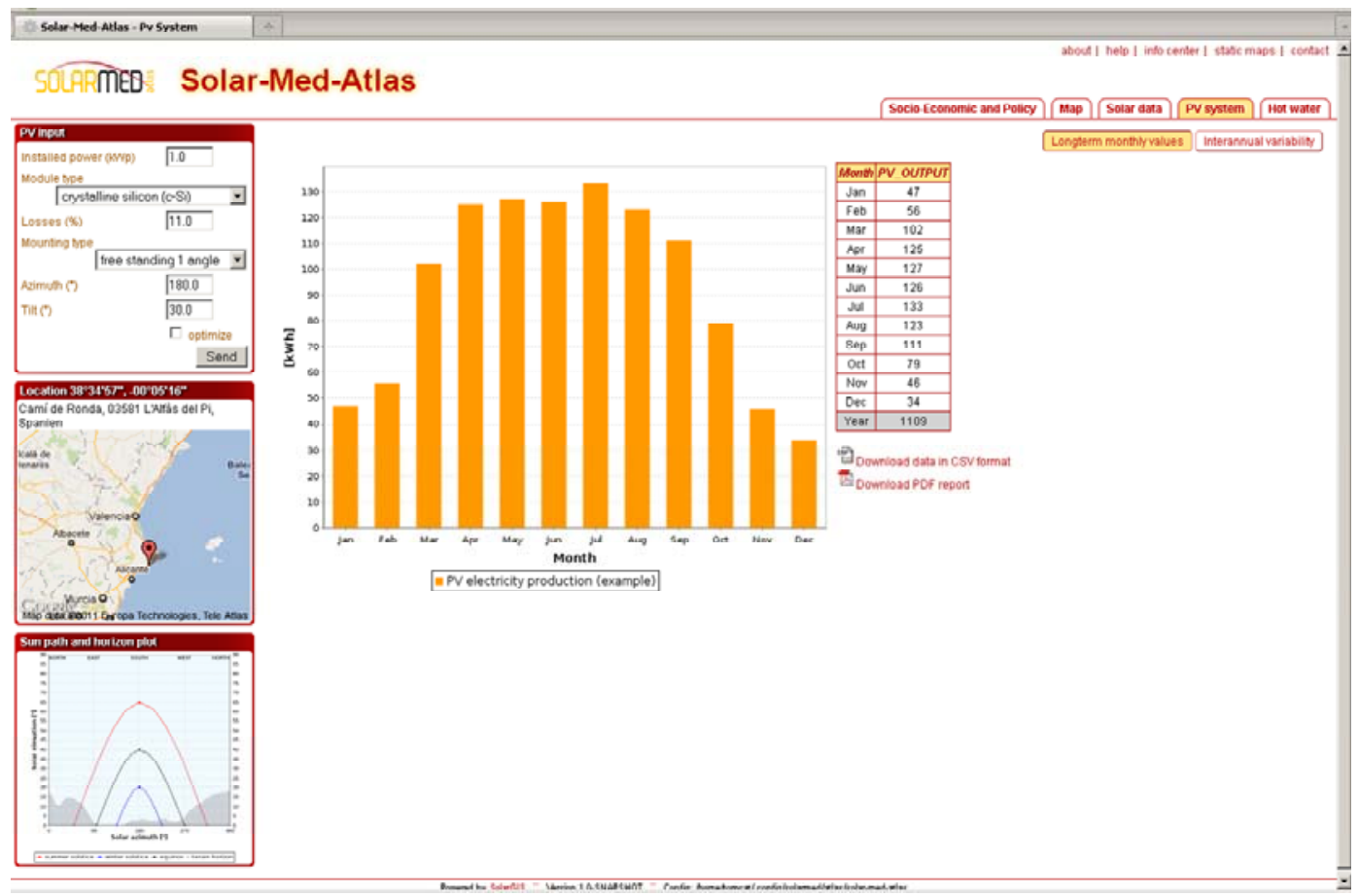

Figure 4: Example of a simple PV-Simulation

The PV system tab is a sample of a simple tool which can be used to estimate the yield of a simple PV system. A few parameters can be adjusted on the top left box as the installed power the module type, losses, the mount type the orientation of the system.

The hot water tap does the same for a small solar water heating system. The performance data can also be downloaded for further analysis or presentation.

\section{Conclusion}

The Solar Atlas for the Mediterranean will bring for the first time a long-term historical solar database in a public domain covering 20 years at $1 \mathrm{~km}$ spatial resolution for the whole region - serving GHI and DNI monthly and annual averages. It will provide an easy to use multilingual user interface with intuitive navigation and innovative features for data provision through a distributed architecture compliant to the GEOSS architecture.

It is believed that with the help of more detailed and up to date solar resource information the Atlas will facilitate development of solar energy projects with an overall aim to save conventional fuel resource, reduce greenhouse gas emissions and create jobs in solar energy business in the region.

To set up a system which is most useful to the users, the project currently needs feedback on the prototype by its potential users in order to tailor the system to the needs of the users. We strongly encourage you to evaluate the prototype at www.solar-med-atlas.com and fill in the user questionnaire.

\section{Acknowledgements}

The work is supported by the German Federal Ministry for Environment, Nature Conservation and Nuclear Safety under the International Climate Initiative, Grand 10_I_130_MED_A_Solar_Resource_Atlas.

\section{References}

[1]www.remap-ec.eu 
[2] Allal, Houda (2009): REMAP Synthesis: Action plan for high priority renewable energy initiatives in Southern and Eastern Mediterranean Area: how to promote wind energy in the Mediterranean region, GEM, Global Energy for the Mediterranean, No. 5, pp. 29-32. Available at www.ome.org

[3] Hoyer-Klick, Carsten / Trieb, Franz / Schillings, Christoph / Allal, Houda / Wald, Lucien / Huld, Thomas (2009): Getting renewable Energy to work: Developing a database for solar energy investment decision in the Mediterranean, GEM, Global Energy for the Mediterranean, No. pp. 33-37. Available at www.ome.org

[4] www.dlr.de/sf/enermena

[5] re.jrc.ec.europa.eu/pvgis

[6] Hammer, A., Heinemann, D., Hoyer, C., Kuhlemann, R., Lorenz, E., Müller, R., Beyer, H.G. (2003): Solar energy assessment using remote sensing technologies, Remote Sensing of Environment 86, 423432.

[7] Schillings, C., Mannstein, H., Meyer, R., (2004): Operational method for deriving high resolution direct normal irradiance from satellite data. Solar Energy 76, 475-484.

[8] Rigollier, C., Bauer, O., Wald, L., (2000): On the clear sky model of the ESRA -european solar radiation atlas -with respect to the heliosat method. Solar Energy 68, 33-48.

[9] www.dlr.de/tt/solemi

[10] www.helioclim.org

[11] Schroedter-Homschedit, Marion / Oumbe, Armel / Hoyer-Klick, Carsten (2010): Aerosol load and dust event mapping based on chemical transport modelling. SolarPaces 2010, Perpignan, France

[12] www.map.ren21.net

[13] www.reegle.info

[14] www.worldbank.org

[15] http://solargis.info

[16] Accessible through www.soda-is.com 